\title{
Bud Dormancy in Perennial Fruit Tree Species: A Pivotal Role for Oxidative Cues
}

\author{
Rémi Beauvieux, Bénédicte Wenden and Elisabeth Dirlewanger* \\ UMR 1332 BFP, INRA, Université de Bordeaux, Villenave-d'Ornon, France
}

For perennial plants, bud dormancy is a crucial step as its progression over winter determines the quality of bud break, flowering, and fruiting. In the past decades, many studies, based on metabolic, physiological, subcellular, genetic, and genomic analyses, have unraveled mechanisms underlying bud dormancy progression. Overall, all the pathways identified are interconnected in a very complex manner. Here, we review early and recent findings on the dormancy processes in buds of temperate fruit trees species including hormonal signaling, the role of plasma membrane, carbohydrate metabolism, mitochondrial respiration and oxidative stress, with an effort to link them together and

OPEN ACCESS

Edited by:

Michael James Considine, The University of Western Australia,

Australia

Reviewed by:

Robert D. Hancock,

James Hutton Institute,

United Kingdom

David Horvath,

Agricultural Research Service (USDA),

United States

*Correspondence:

Elisabeth Dirlewanger

elisabeth.dirlewanger@inra.fr

Specialty section:

This article was submitted to Plant Physiology,

a section of the journal

Frontiers in Plant Science

Received: 16 February 2018

Accepted: 30 April 2018

Published: 16 May 2018

Citation:

Beauvieux $R$, Wenden $B$ and Dirlewanger E (2018) Bud Dormancy in Perennial Fruit Tree Species:

A Pivotal Role for Oxidative Cues.

Front. Plant Sci. 9:657.

doi: 10.3389/fp/s.2018.00657 emphasize the central role of reactive oxygen species accumulation in the control of dormancy progression.

Keywords: bud dormancy, perennial fruit species, hormonal pathways, carbohydrate metabolism, oxidative stress

\section{INTRODUCTION}

In the context of perennial plants, bud dormancy is a crucial step in the phenology cycle, as its progression over winter determines the quality of bud break, flowering and fruiting. The term "dormancy" is associated with temporary suspension of visible growth. It comprises true dormancy ("rest" or "endodormancy") triggered by internal factors, and climatic dormancy ("quiescence" or "ecodormancy") controlled by external factors (Lang et al., 1987; Considine and Considine, 2016). These phases of dormancy are alleviated by different elements: release of endodormancy requires cold accumulation whereas ecodormancy advances with heat accumulation toward bud break. For perennial fruit species, in the context of global warming, endodormancy release may be a critical step in the future due to insufficient chill accumulation, directly affecting flowering quality and uniformity, and thus leading to a drastic reduction of fruit production. In the past decades, much work has been done to unravel the mechanisms underlying dormancy period, and the diversity of approaches used is indicative of the complexity of the trait. Early studies at the beginning of the 20th century mainly dealt with the observation of the phenomenon itself and the effects of dormancy alleviating molecules. In the 70s, advances in microscopy and subcellular techniques allowed novel observations of cellular modifications over the dormancy period. Later, between 1980 and 2000, physiological studies including metabolic analyses led to further description of the main pathways involved, more recently highlighted by genetic and genomic studies. Numerous studies, notably transcriptomic analyses, have led to the identification of common molecular pathways regulating bud dormancy in trees (Rohde et al., 2007; Ruttink et al., 2007; Yamane et al., 2008; Jiménez et al., 2010; Leida et al., 2010; El Kayal et al., 2011; Liu et al., 2012; Bai et al., 2013; Zhong et al., 2013; Xu et al., 2016; Tarancón et al., 2017). Specific gene expression patterns over the course of dormancy featured hormone signaling, carbon metabolism, stress response and chromatin 
modification (Regier et al., 2010; Rios et al., 2014; Saito et al., 2015; Wisniewski et al., 2015; Wen et al., 2016). Among the main pathways identified, the Dormancy-Associated MADS-BOX $(D A M)$ genes have been a constant interest since they were proposed to cause the non-dormant phenotype of the evg mutant of peach (Rodriguez et al., 1994; Bielenberg et al., 2004, 2008; Howe et al., 2015). In peach, the six tandem-arrayed DAM genes display distinct seasonal patterns with peaks in expression at different times during dormancy (Li et al., 2009), supporting their role in promoting and maintaining dormancy (Jiménez et al., 2010; Hao et al., 2015). Following this finding, DAM genes and their involvement in dormancy have been extensively studied in perennial plants including leafy spurge (Horvath et al., 2008; Anderson et al., 2010), apple (Mimida et al., 2015), Japanese pear (Ubi et al., 2010; Saito et al., 2013), tea plant (Hao et al., 2017), Kiwifruit (Wu et al., 2017), and Japanese apricot (Yamane et al., 2008; Sasaki et al., 2011). In poplar, genes homologous to CONSTANS (CO) and FLOWERING LOCUS T (FT) have key roles in the control of dormancy (Böhlenius et al., 2006; Hsu et al., 2011; Srinivasan et al., 2012) and the chill-induced release of endodormancy (Rinne et al., 2011). Recent reviews have nicely described the molecular advances in dormancy studies (Cooke et al., 2012; Rios et al., 2014; Sanchez-Perez et al., 2014) therefore we will not focus our attention on these aspects. Overall, all these pathways are interconnected in a very complex manner and so far no integrative scenario has been proposed to precisely describe their interactions. Nonetheless one particular pathway seems central and is almost always highlighted in the recent studies: the response to oxidative stress and the reactive oxygen species (ROS). Notably, most of the studies using dormancy release substances such as HC (Hydrogen Cyanamide) show they induce the ROS scavenging systems. Interestingly, ROS are also thought to be a key signal during plant development for many aspects including dormancy (Considine and Foyer, 2014), as shown by their link to the hormonal interplay, cell wall loosening, and ion channels in seeds. Here, we review both early and recent findings on the dormancy processes in buds of temperate fruit trees species including hormonal signaling, the role of plasma membrane, carbohydrate metabolism, mitochondrial respiration and oxidative stress, with an effort to link them together and emphasize the central role of ROS accumulation in the control of endo- and ecodormancy progression.

\section{OXIDATIVE STRESS AND REDOX CUES}

In contrast to chilling-induced breaking of dormancy, exposing dormant buds to sub-lethal freezing and high temperatures as well as other sub-lethal treatments for a short period of time can overcome rest relatively rapidly (Orffer and Goussard, 1980; Nee and Fuchigami, 1992). Following these observations, numerous lines of evidence have highlighted that stresses, especially oxidative and respiratory stresses, are involved in the release of buds from dormancy. These stresses trigger the production of ROS, which have been shown to be critical throughout plant life and development (Considine and Foyer, 2014). This production of ROS including $\mathrm{H}_{2} \mathrm{O}_{2}$ in buds suggests that they may act as key signaling molecules for dormancy release (Kuroda et al., 2002, 2005; Pérez and Burgos, 2004; Prassinos et al., 2011; Vergara et al., 2012; Hussain et al., 2015; Tan et al., 2015). These hypotheses are further supported by observations that exogenous $\mathrm{H}_{2} \mathrm{O}_{2}$ can substitute for chilling, thus confirming that an increase in $\mathrm{H}_{2} \mathrm{O}_{2}$ levels may activate the sequence of reactions involved in the breaking of bud dormancy (Pérez and Burgos, 2004; Kuroda et al., 2005; Pérez et al., 2008). Conversely, treatment of potato tuber with a NADPH oxidase inhibitor leads to decreased ROS production and delayed dormancy release (Liu et al., 2017). In plant cells, ROS are continuously produced as a consequence of aerobic metabolism in all the intracellular organelles. Cells have the capacity to rapidly produce and scavenge different forms of ROS levels, as a result of a balance between formation and detoxification rates, with a tight link to cellular metabolism, making ROS good signals to monitor changes in cellular metabolism (Mittler et al., 2011). Another indication that oxidative stress is an important part of the process of dormancy is that antioxidant defense and detoxification pathways are upregulated during dormancy release, including catalase (CAT), glutathione peroxidase (GR), superoxide dismutase (SOD), ascorbate peroxidase (APX) and peroxidase superfamily proteins (Scalabrelli et al., 1991; Or et al., 2000; Halaly et al., 2008; Leida et al., 2010; Prassinos et al., 2011; Vergara et al., 2012; Viti et al., 2012; Bai et al., 2013; Zhuang et al., 2013; Guzicka et al., 2017). This is especially true for buds treated with dormancy-breaking compounds. In apricot flower buds, gibberellic acid $4\left(\mathrm{GA}_{4}\right)$ treatment upregulates oxidation-reduction proteins and the authors hypothesized that $\mathrm{GA}_{4}$ application led to the development of oxidative stress and to subsequent dormancy release (Zhuang et al., 2013). HC has been widely used by growers to overcome low and uneven bud break and the mechanisms that underlies its dormancybreaking effect is extensively studied in fruit species. Many studies show that a significant increase in $\mathrm{H}_{2} \mathrm{O}_{2}$ levels is the main metabolic change produced by $\mathrm{HC}$, often linked to an inhibition of CAT activity (Bartolini et al., 1996; Pérez and Lira, 2005; Halaly et al., 2008; Pérez et al., 2009; Tan et al., 2015). However, recent genomic studies show that a wide range of genes is differentially regulated after $\mathrm{HC}$ application such as genes related to cell wall loosening, hormonal response, carbohydrate and protein metabolism (Ophir et al., 2009; Pérez et al., 2009; Liu et al., 2015; Sudawan et al., 2016; Ionescu et al., 2017) thus linking oxidative stress, mitochondrial activity, hypoxia, cytokinins, auxin, jasmonate and ethylene signaling pathways to $\mathrm{HC}$-induced dormancy release. Based on these findings, $\mathrm{HC}$ application is thought to trigger transient oxidative stress and activate detoxification systems. Subsequently, most pathways proposed to be involved in dormancy release are activated: degradation of callose, inhabitation of abscisic acid (ABA), GAs, glycolysis, cytokinins (Ophir et al., 2009; Pérez et al., 2009; Zheng et al., 2015; Ionescu et al., 2017). Another clue for the involvement of ROS during dormancy is the response of several ROS scavenging systems that were closely analyzed during bud dormancy. The glutathione and ascorbate pathways are crucial for the detoxification of $\mathrm{H}_{2} \mathrm{O}_{2}$. The overall content of glutathione was shown to increase in concomitance with the endodormancy 
overcoming. Moreover, the ratio between reduced (GSH) and oxidized (GSSG) glutathione, was reported to be associated to the dormancy stage: higher levels of GSH at the end of rest compared to beginning of the phase (Siller-Cepeda et al., 1992; Wang and Faust, 1994; Kocsy et al., 2001; Bartolini et al., 2006). This ratio has been shown to be under the control of the glutathione reductase (GR) activity in Japanese pear (Zanol et al., 2010). In dormant grapevine buds, HC upregulates genes involved in ascorbate, glutathione and pentose phosphate pathway (PPP) detoxification pathways (Pérez et al., 2009; Sudawan et al., 2016). Temporary induction of the PPP in response to oxidative stress may provide a way to recharge the system with NADPH for detoxification through the ascorbate/glutathione system (Figure 1). Such an induction has been observed in apricot buds after a treatment with $\mathrm{GA}_{4}$ (Zhuang et al., 2015), thus allowing the production of NADPH in the absence of mitochondrial respiration. All these studies provide evidence that ROS play a crucial role during dormancy and raise the questions of the mechanism involved in the oxidation system, especially how other pathways interact or are directly controlled by oxidative cues.

\section{MITOCHONDRIAL RESPIRATION}

Mitochondrial respiration is the primary cellular source of ROS on non-photosynthetic tissues in the context of healthy conditions (Van Aken et al., 2009), whereas plasma membrane and cell-wall NADPH/NADH oxidases are major producers in the context of defense response (Davies et al., 2006). An elevation of ROS production is noted in abnormal conditions, such as hypoxia or hyperoxia (Turrens, 2003). During dormancy, hypoxia and the inhibition of mitochondrial respiration can be responsible for the increase in ROS content observed in dormant buds (Vergara et al., 2012; Meitha et al., 2015, 2018), potentially by activating gluconeogenesis, and therefore enhances grape bud dormancy release (Ophir et al., 2009; Rubio et al., 2014; Sudawan et al., 2016). Likewise, $\mathrm{O}_{2}$ deprivation raises glycolysis and ethanolic fermentation which could lead to the production of ROS (Pérez et al., 2009). Moreover, treatment of isolated grape bud mitochondria with sodium azide, another dormancy release molecule, inhibited $\mathrm{O}_{2}$ uptake (Pérez et al., 2009) and mitochondria under hypoxia have been shown to have less TCA cycle enzyme activities and reduced ATP production in maize and potato (Considine et al., 2017). In response to shortening photoperiod and low temperature, respiration may be impaired as part of the growth cessation and dormancy onset processes. For example, ABA, which participates to dormancy maintenance, has been shown to inhibit certain isoforms of the tricarboxylic acid (TCA) cycle isozymes in floral buds of peach (Oncelay et al., 1979) or sucrose transporters in vine (Murcia et al., 2015), thus comforting the hypotheses that respiration processes are affected during dormancy. All these elements suggest that a respiratory stress must be involved in the release of buds from dormancy through abnormal positive net production of ROS.

Regulation of respiration is central to the transition from rest to metabolically active state, generating the ATP needed for cell functioning and growth. In aerobic respiration, mitochondria carry out the final steps of this process and generate the bulk of ATP through (i) the TCA cycle, (ii) the oxidative phosphorylation electron chain, (iii) the alternative oxidase (AOX), and (iv) the set of carriers and channels that provide the substrates and cofactors from the cytosol. Respiration rate and depth of dormancy were shown to be inversely related in grapevine buds (Parada et al., 2016), associated with contrasted response to temperature and glucose, two stimuli that normally increase respiration in plant tissues. While respiration in non-dormant buds rose sharply in response to both stimuli, respiration in dormant buds was only slightly affected, thus suggesting that respiration is inhibited in dormant buds. Several processes can explain this repression of mitochondrial respiration during dormancy. Firstly, some studies report that mitochondria activity might be altered over dormancy progression, with modifications in their number (Felker et al., 1983) or their structure (Guzicka et al., 2017), and could be linked to availability of oxygen and requirements of oxidative phosphorylation (Considine et al., 2017). Thereafter, respiration in dormant bud cells might be affected. Secondly, as described before, dormant cells are subjected to carbon starvation and repression of cell-to-cell transport, coupled with bud scales that have low oxygen permeability. Analyses of gene expression and $\mathrm{O}_{2}$ pressure measurements suggest that dormant buds reside in a hypoxic state and return to the oxygenated state during bud burst (Meitha et al., 2015). According to experiments on $\mathrm{O}_{2}$ consumption and $\mathrm{CO}_{2}$ production of grapevine twigs in hypoxic conditions (solution of chlorpromazine) or normal conditions, fermentation pathway has been suspected to be involved in dormancy release (Pouget, 1965). Recent findings on transcript abundance of key genes such as lactate dehydrogenase or alcohol dehydrogenase tend to confirm the activation of the fermentation pathway in dormant bud cells under chilling or dormancy-breaking reagent treatments (Or et al., 2000; Halaly et al., 2008; Ophir et al., 2009; Pérez et al., 2009), which is characteristic of low-oxygen conditions. Furthermore, plasma membrane properties are modified during dormancy and we hypothesize that chill modifies the properties of membranebound proteins, as was shown for the succinate oxidase activity for mitochondria of Jerusalem artichoke tubers (Chapman et al., 1979): the Arrhenius activation energy was high during dormancy and decreased at the termination of dormancy. Finally, it has been proven that the level of ATP or the ATP/ADP ratio change over dormancy progression: low levels of ATP are characteristic of endodormancy while a steep rise in ATP/ADP ratio marks the end of ecodormancy (Bonhomme et al., 2000). The mitochondrial ATP synthase complex requires inorganic phosphate delivery by the mitochondrial phosphate transporter (MTP). The expression level of MPT is low during dormancy and up-regulated to promote respiratory rate and energy metabolism for bud dormancy release in tree peony (Huang et al., 2008; Zhang et al., 2016). These results are consistent with the hypothesis that phosphate is compartmentalized during dormancy (Bonhomme et al., 2000) leading to the inhibition of respiration and ATP production.

According to all these knowledge, the role of the mitochondrial respiration during the different phases of 


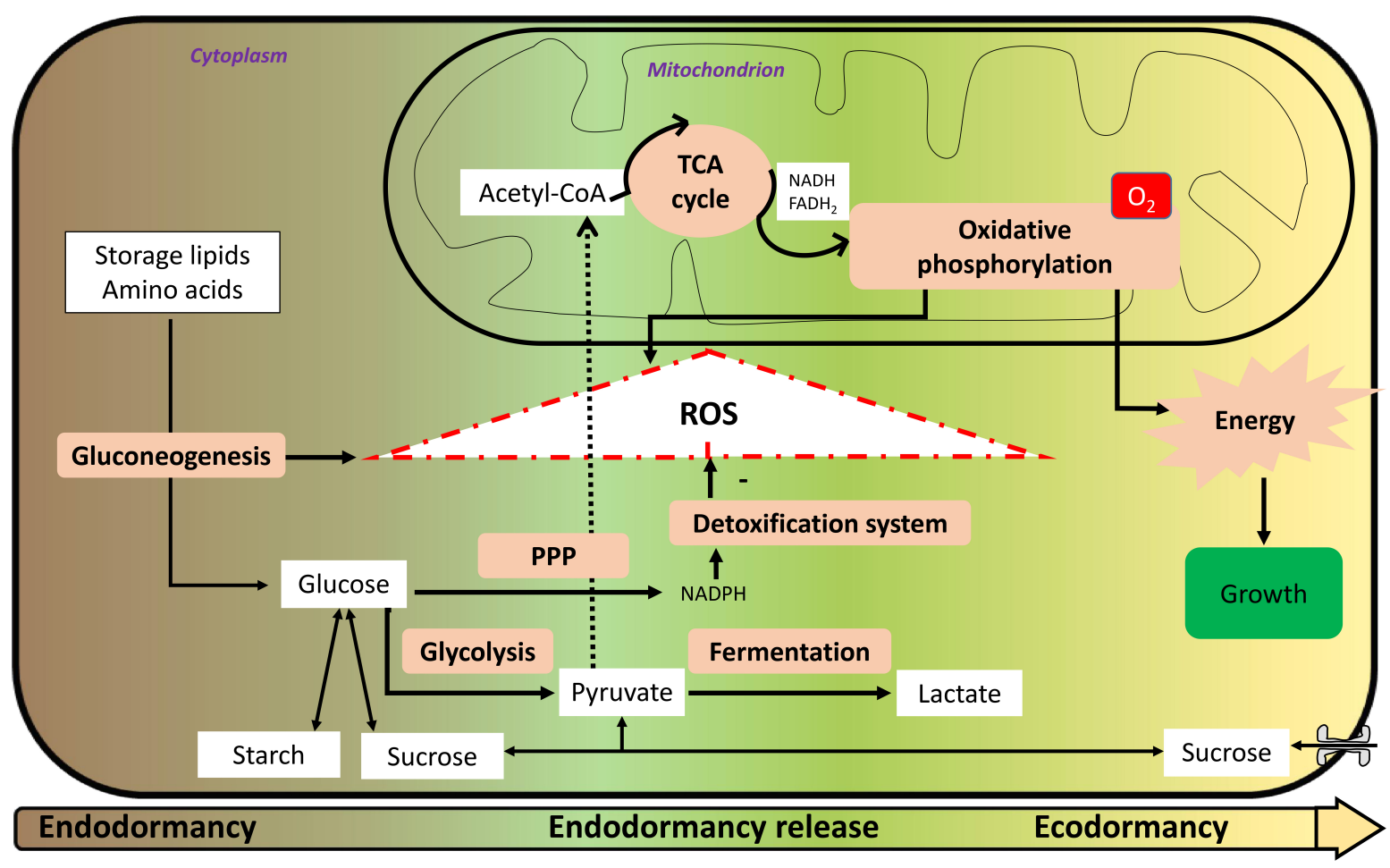

FIGURE 1 | Metabolism and reactive oxygen species (ROS) formation from endodormancy until ecodormancy. From endodormancy to ecodormancy, metabolism is of primary importance. Storage lipids and amino acids are degraded through the gluconeogenesis pathway to yield glucose. Glucose car be interverted to starch and/or sucrose. It can also be degraded through the glycolysis pathway to yield pyruvate that will migrate to the mitochondria and will be metabolized through the tricarboxylic acid (TCA) cycle to enable oxidative phosphorylation to occur with reducing power in the form of nicotinamide adenine dinucleotide (NADH) and flavine adenine dinucleotide $\left(\mathrm{FADH}_{2}\right)$. This progressive reactivation of oxidative phosphorylation during endodormancy release is partly responsible for ROS formation with gluconeogenesis. Glucose may also be oxidized via the pentose phosphate pathway (PPP) to yield reducing power in the form of nicotinamide adenine dinucleotide phosphate (NADPH), enabling the detoxification system to operate. During endodormancy release period, there is a net positive accumulation of ROS that trigger mechanisms of endodormancy release. During ecodormancy, oxidative phosphorylation is more efficient and enable energy production and mechanisms of growth that are necessary for bud bursting and flowering.

dormancy is proposed in Figure 1: during endodormancy, hypoxia and the inhibition of mitochondrial respiration can be responsible for the increase in ROS content that reach a maximum at the endodormancy release, and at this stage, recovery of mitochondrial respiration during the ecodormancy period.

\section{CARBOHYDRATES METABOLISM}

In addition to the role of mitochondrial respiration toward positive ROS production, carbohydrate metabolism seems to be crucial for ROS systems. During dormancy, a carbon starvation is noted, and glucose is a key molecule. It may be produced via storage molecules such as lipids, notably through beta-oxidation and neoglucogenesis, responsible for a net ROS production (Dieuaide et al., 1992). On one hand, glucose may be processed in the glycolysis and then metabolized in the mitochondria for ROS production; on the other hand, it may be processed through the PPP to yield reducing power and participate to ROS detoxification. For example, in yeast, it has been shown that low glucose amounts induce a decreased mitochondrial ROS production (Barros et al., 2004). Interestingly, it has been shown that a switch from glycolysis to PPP during germination in Arabidopsis seed is a scavenging system for oxidative stress (Arc et al., 2011).

In addition to its crucial role in the response to cold, carbohydrate metabolism appears essential in the transition from dormancy to active bud growth (Figure 1), as suggested by Park et al. (2009) and Signorelli et al. (2018). Changes in carbohydrate dynamics were linked to changes in dormancy status in sweet cherry with a degradation of starch into soluble sugars during dormancy onset and an increase in starch just before budburst (Kaufmann and Blanke, 2017). In parallel with starch dynamics, soluble sugars were shown to increase between autumn and winter followed by a significant decrease between winter and spring (Charrier et al., 2017). The bud capacity to burst is tightly linked to its supply in carbohydrates and as described previously, the carbohydrate uptake capacity increases in the bud after dormancy release with an increase in the expression and activity of plasma membrane transporters. Just before budburst, all sugars are transported in the sap toward the buds but during endodormancy, carbohydrate dynamics are restricted to the bud tissues. Tarancón et al. (2017) proposed that growth 
cessation and bud dormancy are consequences of carbon supply starvation syndrome linked to the sugar deficit. Over dormancy progression, and in response to winter conditions, soluble compounds (sucrose, glucose) are synthesized from the reserves accumulated during the growing season, such as starch grains (Felker et al., 1983; Guzicka, 2001; Xu et al., 2016; Guzicka et al., 2017). Interestingly, poplars overexpressing sucrose phosphate synthase - which accumulate more sucrose and starch than the wild-type poplars - are characterized by accelerated bud break, raising the possibility that enhanced sugar and/or starch reserves can promote accelerated dormancy breaking (Park et al., 2009). However, in the context of low carbon supply, it is possible that the gluconeogenesis pathway is activated to produce glucose from non-carbohydrate sources (Figure 1) as reported by Ruttink et al. (2007), associated with the generation of ROS. Similar pathway was described in dormant seeds (Einali and Valizadeh, 2017). In addition, a recent study showed that sucrose was synthesized during $\mathrm{GA}_{4}$-induced dormancy release (Zhuang et al., 2015), thus confirming the link between soluble sugars content and end of endodormancy.

During dormancy, glucose is metabolized in at least three pathways involved in the cell processes: the PPP leading to a detoxification system, glycolysis that synthesizes the pyruvate necessary for mitochondrial respiration, and fermentation producing lactate (Figure 1). We propose that the balance between all three pathways is key in the control of dormancy release.

\section{HORMONAL SIGNALING}

Phytohormones are plant molecules that are produced within the plant and control most, if not all, developmental aspects of plant life (Davies, 2013). ROS and hormones have been shown to act in an interdependent manner (Barba-Espin et al., 2010; Bahin et al., 2011; Oracz and Karpiński, 2016). For example, a recent study has shown this close link between the pathways with an inhibition of ROS formation by ABA, and a promotion of ROS formation by gibberellins (GAs) in seeds during cold stratification (Amooaghaie and Ahmadi, 2017), and conversely ROS mediate ABA and GA regulation through their catabolism and biosynthesis, respectively (Liu et al., 2010).

Hormonal pathways, including ABA, GAs, ethylene, auxin and cytokinins, have been demonstrated to be of great importance in the bud dormancy process (Mielke and Dennis, 1978; Rodríguez and Sánchez-Tamés, 1986; Wang et al., 1987; Piola et al., 1998; Ophir et al., 2009; Doğramac1 et al., 2013; Zhuang et al., 2013; Wen et al., 2016; Signorelli et al., 2018). Auxins were reported to be present at different concentration in buds throughout dormancy progression. Dormancy onset and cold treatment induces a reduction in auxin while quantity of auxins rises in ecodormancy until budburst as shown in hazelnuts (Rodríguez and SánchezTamés, 1986) and grapevine (Aloni et al., 1990). It has been shown that auxins can be oxidized by two mechanisms in plants, a $\mathrm{H}_{2} \mathrm{O}_{2}$ dependent pathway, and a molecular dioxygen pathway, via peroxidases and membrane-bound
NADPH oxidases (Pfeiffer and Höftberger, 2001; Kawano, 2003). Oxidation of auxin may thus yield ROS and be part of their generation during endodormancy progression. In addition, it has been shown in apple that genes related to auxin transport are major regulators of dormancy (Porto et al., 2015), and thus we could make the hypothesis that auxins may be involved to the propagation of the ROS signal through different territories, as this ROS signal propagation has been shown in grape buds during bud bursting (Meitha et al., 2015). Transcriptomic analyses of dormant buds suggest that brassinosteroid, salicylic-acid-, and jasmonic-acid-associated genes are differentially regulated during dormancy (Howe et al., 2015). The ethylene pathway is interesting when focusing on dormancy and oxidative stress signaling. Indeed, ethylene induced bud break in grapevine buds (Ophir et al., 2009) and low-temperature stress and HC treatment, closely linked to oxidative cues as stated before, provoke ethylene biosynthesis, associated with chilling requirement and dormancy release in peach and sweet cherry (El-Shereif et al., 2006; Del Cueto et al., 2017). In addition, the ethylene biosynthesis pathway, starting with ethylene precursors methionine and ACC, increases during endodormancy, resulting in the production of ethylene but also of hydrogen cyanide, therefore leading to increased levels of ROS (Ionescu et al., 2017). In seed dormancy, $\mathrm{ABA}$ and GAs act antagonistically thus it is not surprising that both pathways and their interaction have been closely studied in the context of bud dormancy (Rodríguez-Gacio Mdel et al., 2009). ABA has been demonstrated to promote shoot growth cessation and bud dormancy establishment (Le Bris et al., 1999; Guak and Fuchigami, 2001) whereas GA promotes growth and dormancy release (Rinne et al., 2011). In fruit trees, increases in bud ABA content have been reported at the beginning of endodormancy in the fall (Götz et al., 2014; Wang et al., 2016; Tuan et al., 2017; Li et al., 2018) followed by a rapid drop in response to cold (Leida et al., 2012) or dormancy-breaking agents (Seif El-Yazal et al., 2014; Zheng et al., 2015), accompanied by changes in the expression of genes related to ABA biosynthesis and degradation. Several studies showed that the expression of 9-cis-epoxycarotenoid dioxygenases (NCED), involved in ABA synthesis, is activated during dormancy induction and maintenance (Fennell et al., 2015; Wang et al., 2016; Chao et al., 2017; Li et al., 2018). In addition, after chilling requirements are satisfied, $A B A$ levels decrease under the control of $A B A$ $8^{\prime}$-hydroxylase (encoded by CYP707A), which is up-regulated during dormancy release (Zhang et al., 2015; Wang et al., 2016; Tuan et al., 2017; Li et al., 2018). Alternatively, inhibition of active ABA might be related to the production of conjugated forms of $\mathrm{ABA}$ that increases in response to cold temperatures: glucose ester of ABA (ABA-GE) in Vitis (Koussa et al., 1994) and an ABA-isomer in cherry (Götz et al., 2014). Interestingly, recent studies have indicated that early cultivars of Japanese apricot contained less ABA during dormancy than late cultivars (Wen et al., 2016), thus suggesting a dose-dependent control of dormancy. Interestingly, a close relationship between ABA and ROS has been shown not only during stomatal closure but also for seed dormancy. Notably, exogenous ROS application diminished ABA concentration in barley seeds during the afterripening period (Wang et al., 1998), and increased its catabolism 
by up-regulating CYP707A genes in Arabidopsis during seed imbibition (Liu et al., 2010). Moreover, treatment of sunflower seeds during this after-ripening period enhances ROS production (Oracz et al., 2007), similarly to many studies including HC treatment on bud in various species. Thus, even though no studies have demonstrated these connections of ROS and ABA in buds, they are well known in various seed tissues. Therefore, as proposed by Leida et al. (2012), similar mechanisms may occur in bud dormancy. More precisely, we may compare the seed after-ripening period with bud endodormancy stage, while the imbibition process in seed may be similar to the ecodormancy period in buds. Nevertheless, the effect of ABA on bud dormancy is still not entirely understood, and ABA may control growth inhibition rather than play a direct role on dormancy regulation as suggested by Ramina et al. (1995) when they did not identify any strict relationship between ABA quantity and dormancy release in peach buds. Sensitivity to ABA may fluctuate as well, as shown in dormant pea seedling, where ROS inhibits the ABA signaling pathway during the imbibition period (Meinhard and Grill, 2001; Barba-Espin et al., 2010).

Gibberellic acids are particularly important as they may act in the growth renewal process during dormancy release. In fruit trees, several studies pointed out their implication in the control of dormancy progression, although few studies quantified them directly, but focused on their metabolism and on the effect of exogenous application. GA application may even substitute for chilling (Brown et al., 1960; Saure, 1985; Reinoso et al., 2002; Rinne et al., 2011; Zhuang et al., 2013) and GAs synthesis is promoted by dormancy breaking reagents (Seif El-Yazal et al., 2014). Nevertheless, the highest levels of $\mathrm{GA}_{1}$ and $\mathrm{GA}_{3}$ were found in dormant buds during endodormancy release and diminished afterwards (Luna et al., 1990; Wen et al., 2016). Overall, this is supported by expression analyses, with the upregulation of GA3-oxidase (GA3ox) and GA20-oxidase (GA20ox), responsible for bioactive GA synthesis, under chilling treatment (Rinne et al., 2011) or around dormancy release (Bai et al., 2013; Wen et al., 2016). GA2-oxidase (GA2ox) genes, which encode the enzymes responsible for the deactivation of bioactive $\mathrm{GA}_{4}$ and $\mathrm{GA}_{1}$, are upregulated during dormancy and dormancy release in Japanese apricot buds (Yamane et al., 2008) but during ecodormancy as well in Japanese pear (Bai et al., 2013). Thus it appears that GAs regulation is tightly balanced between production and degradation, and they might enhance growth rate when the conditions are favorable. Interestingly, endogenous ROS application enhances endogenous GA concentration in Arabidopsis seed (Bahin et al., 2011) through diminution of its catabolism, and conversely $\mathrm{GA}_{4}$ application in apricot flower buds led to the development of oxidative stress and subsequent dormancy release (Zhuang et al., 2013). Thus there is obviously a tight link between ROS and GA, both influencing each other.

Taken as a whole, we can postulate that, similarly to seed dormancy, the hormonal balance between ABA and GA, which promotes dormancy and growth, respectively, may mediate the decision toward bud break, and as stated previously for different hormonal studies. Furthermore, as shown for the interaction between ethylene and $\mathrm{ABA}$, ethylene modulating ABA degradation and signaling (Zheng et al., 2015), all hormonal pathways are interconnected and act together to control dormancy progression this balance may be directly influenced by ROS content, notably through redox control of the activity and symplasmic and apoplastic transport of plant growth regulator or transcriptions factors (Considine and Considine, 2016).

\section{PLASMA MEMBRANE AND CELL WALL MODIFICATIONS}

On another scale, modifications of membrane structure may be influenced by ROS concentration, or may be responsible for changing metabolism and thus may enhance ROS production. For example, $\mathrm{O}_{2}$ diffusion through membranes may be more effective just before endodormacy release, inducing metabolism activity and then the increase of ROS production. On the other hand, as proposed above, ROS production may be caused by hypoxia. It is therefore essential to understand whether membrane modifications induce ROS production by raising metabolism as oxygen is more available, or if oxygen shortage generates ROS (Turrens, 2003). Molecular and metabolic changes associated with seasonal cycle of dormancy have been studied extensively in trees but structural changes at the cell level were less examined. Cells are organized in different compartments that enable their normal functioning. These compartments are delimited by membranes that are bilayers of complex lipids, partly permeable, associated with proteins (Figure 2). The stability of the membranes under cold stress highly depends on their functional and structural characteristics therefore the role of its components, lipids and proteins, is crucial. During winter, both dormancy and cold acclimation modify the cell structure and the two processes are usually difficult to separate. The lipid composition and membranous factors are modified during dormancy, notably to protect the cells from freezinginduced dehydration and lesions (Wang and Faust, 1990; Uemura and Steponkus, 1999). For example, it has been shown that the fluidity of the plasma membranes of bud cells in peach increases with chilling during dormancy release (Portrat et al., 1995), associated with a marked increase in total phospholipid content and in the relative level of linolenic acid (C18:3) (Erez et al., 1997). Moreover, low temperatures or thidiazuron, a growth regulator, increases the degree of unsaturation of fatty acids in the membrane lipids of apple buds, changes the polar head group composition, and changes sterol levels and composition (Wang and Faust, 1988, 1990). In addition, triggering dormancy release by $\mathrm{GA}_{4}$ application further confirmed that the composition in linoleic and linolenic acids are modified during dormancy progression (Zhuang et al., 2015).

Thus, winter cold temperatures lead to modifications in the membrane state as part of the cold acclimation process but also potentially the dormancy state. Nevertheless, no studies have been undertaken concerning the global lipid composition during the dormancy period with a lack of chilling, thus allowing a better understanding of the role of lipids over winter and spring rest. Studies investigating ultrastructure changes during dormancy are still rare but exceptions includes: plasmodesmata and lipid droplets analyses (Rinne and van der Schoot, 2004; 


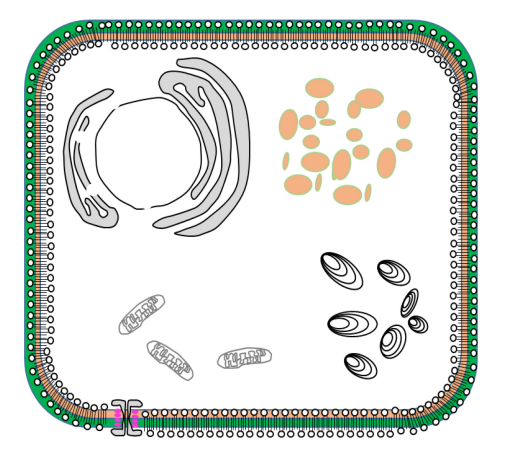

Endodormancy Transition

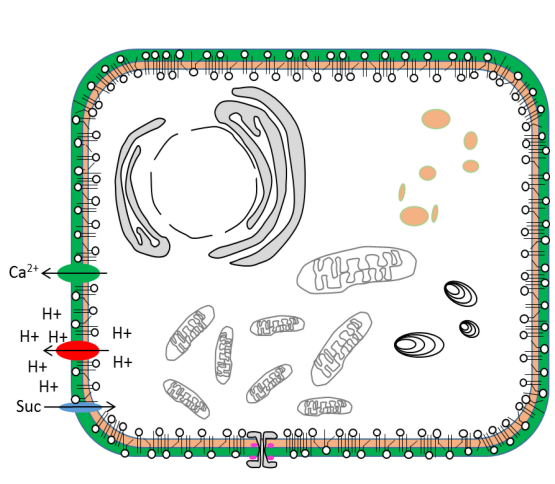

Ecodormancy

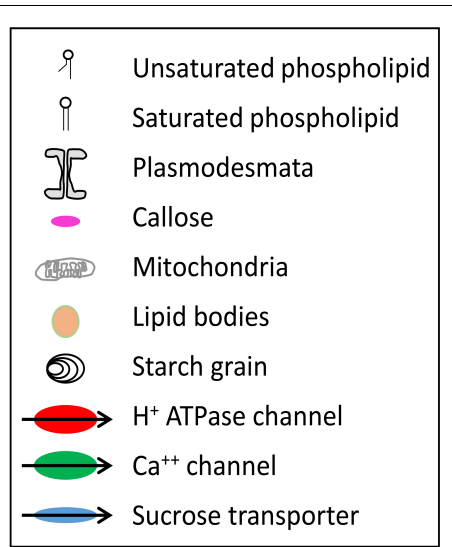

FIGURE 2 | Cellular structure modifications from endodormancy to ecodormancy. During transition from endodormancy to ecodormancy in dormant buds, several structure modifications occur. The insaturation degree of plasma membrane lipids increases during transition from endo to ecodormancy. The number and size of starch grains and lipid bodies decrease during the transition from endo to ecodormancy. Conversely, the number and size of mitochondria increases during the transition from endo to ecodormancy. Transcripts of sucrose transporters, H+/ATPase channels and calcium channels increase during transition from endo to ecodormancy. The size of plasmodesmata increases during transition from endo to ecodormancy, as a result of net callose degradation.

Rinne et al., 2011; Paul et al., 2014) and cell wall thickening and an increase in vacuole precipitates during dormancy induction (Jian et al., 1997). Currently, no study has shown a direct relationship between ROS signaling and membrane modification in bud dormancy but analyses on seed germination have shown that hydroxyl radical $\mathrm{OH}$ - had a direct role on degradation involved in cell wall loosening (Müller et al., 2009). Therefore, we can hypothesize that ROS signaling may be involved in downstream cell wall loosening during bud dormancy release and growth resumption.

\section{ROLE OF MEMBRANE BOUND TRANSPORTERS}

Apart from the changes in the saturation level of the lipids and types of lipids, other properties of the membranes are modified over dormancy progression (Figure 2). In particular, movements through the plasma membrane and long-distance transport change in response to chilling. In peach for example, active absorption of sucrose and other nutrients is stopped when the bud is in a state of deep dormancy while an active sucrose import was observed during growth resumption (Marquat et al., 1996). These modifications in cotransport $\mathrm{H}+$ /sucrose can be explained by structural changes of the plasma membrane (Wisniewski and Ashworth, 1986; Portrat et al., 1995), and more specifically by changes in ATPases activity (Giaquinta, 1979) (Figure 2). Plasma membrane $\mathrm{H}^{+}$extrusion pumps (PM $\mathrm{H}^{+}$/ATPases) are key players in transport activity through their role in energizing solute transport (Alves et al., 2001) and studies revealed that $\mathrm{H}+/ \mathrm{ATPases}$ accumulation and activity are inhibited during endodormancy (Aue et al., 2000) but increase during endodormancy release or ecodormancy in peach (Gévaudant et al., 2001), walnut (Alves et al., 2007), and pear (Liu et al., 2012) (Figure 2). In the same time, the hydric status of buds varies characteristically with a marked dehydration in endodormancy and a water content increase in ecodormancy, just before budburst (Rinne et al., 1994; Yooyongwech et al., 2009; Götz et al., 2014; Kaufmann and Blanke, 2017). Water content was reported to increase in peach buds after a treatment with $\mathrm{HC}$, a dormancy-breaking agent, suggesting that not only cold regulates the hydric status (Yooyongwech et al., 2012). The water status in buds is controlled by a range of membrane bound channels like aquaporins. Transcripts for two aquaporins showed differential spatiotemporal patterns in dormant peach buds in an interesting study by Yooyongwech et al. (2008). Their observations revealed that the activation of inter- and intra-cell communication through aquaporins resulted in a gradual increase in water content before growth resumption, which occurs earlier in low-chill cultivars than in high-chill cultivars.

Furthermore, connections between cells and organs over dormancy progression rely on the plasmodesmata functioning for carbohydrate and nutrient supply as well as signaling molecules. Plasmodesmata are not only essential for cell-to-cell transport, thus crucial for the bud functioning during dormancy, but they also control the supply route through the phloem between the buds and the shoot. Consequently, modifications of the transport activity by obstruction of the plasmodesmatal system lead to growth cessation, dormancy onset and dormancy release (Rinne and van der Schoot, 1998; Rinne et al., 2001; $\mathrm{Xu}$ et al., 2016). In their exhaustive review on plasmodesmata, Rinne and van der Schoot (2003) demonstrated the key role of plasmodesmata activity for symplasmic uncoupling and recoupling of vegetative bud cells during dormancy onset and dormancy release, respectively. In dormancy-inducing conditions, several studies have shown that callose $(1,3-\beta-D-$ glucan) is deposited at the bottleneck region of plasmodesmata leading to diminished, if not stopped, transport and signaling between cells (Rinne et al., 2001). Net callose deposition is governed by the joint action of $1,3-\beta$-glucansynthases and 1,3$\beta$-glucanases (glucan hydrolase family 17, GH17), and shifts in 


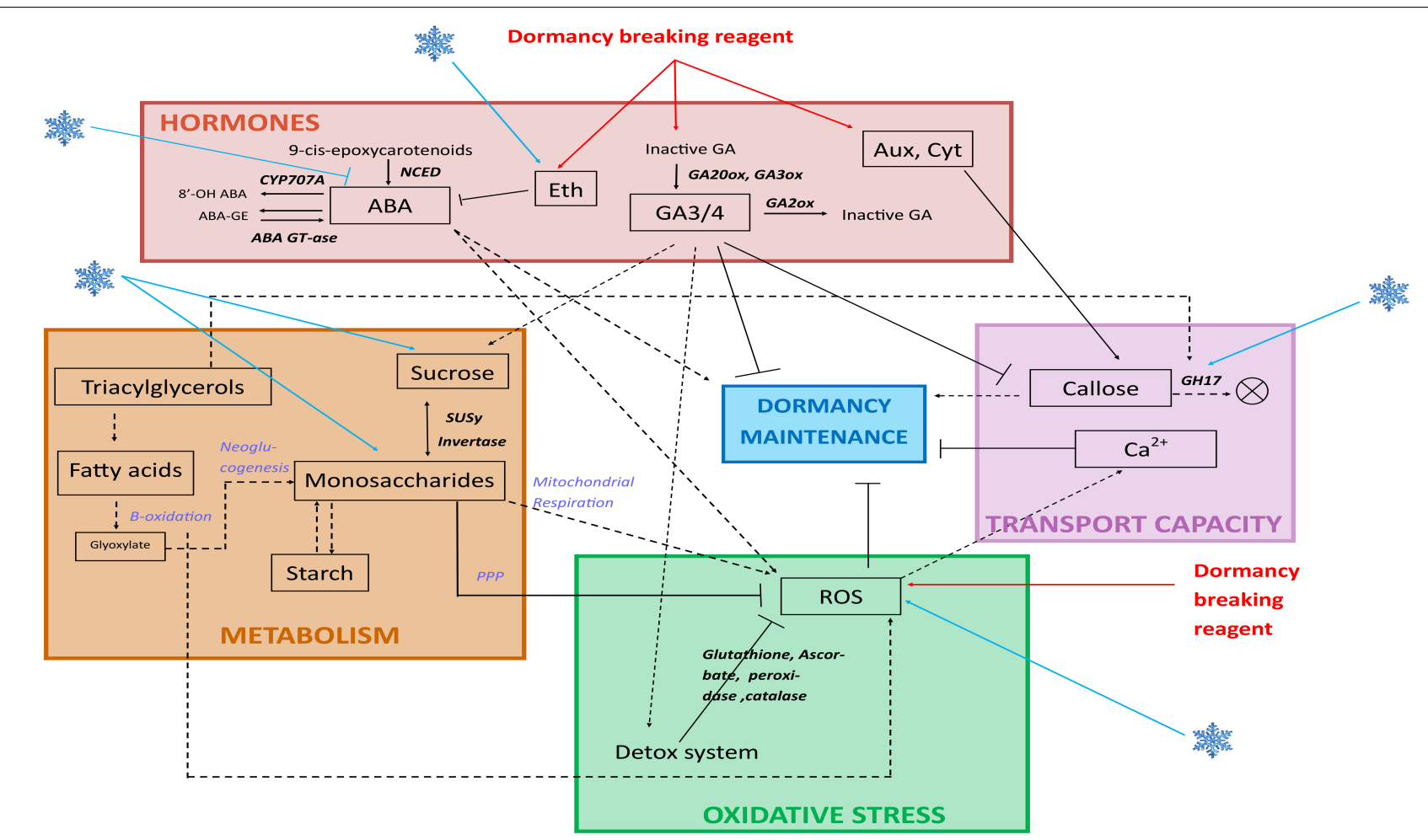

FIGURE 3 | Dormancy pathways and their interactions. During dormancy, several pathways have been shown to have a role and relate to each other. Hormones: abscisic acid (ABA) turnover is regulated through action of 9-cis-epoxycarotenoid dioxygenases (NCED) genes which are repressed by the action of cold temperatures, and is involved in dormancy maintenance and reactive oxygen species (ROS) generation. Ethylene production is under control of cold temperatures (blue flake) and dormancy breaking reagents, and is involved in ABA diminution. Active gibberellic acids (GA) are produced by GA20ox and GA3ox, and are involved in dormancy alleviation and favourise the detoxification system; they are inactivated by GA2ox. Auxins and cytokinins act through enhancing callose deposition at plasmodesmata. Transport capacity: callose deposition at plasmodesmata is involved in dormancy maintenance; Glycoside Hydrolases 17 (GH17) are involved in digesting callose. Cold temperatures enhance GH17 expression. Calcium channels inhibit dormancy maintenance. Metabolism: cold temperatures enhance sucrose and monosaccharides concentration. Monosaccharides are also produced from the beta-oxidation and neoglucogenesis from fatty acids, and these monosaccharides produce ROS via mitochondrial respiration or are oxidized via the Pentose Phosphate Pathway (PPP) and participate to ROS detoxification. beta-oxidation produces ROS. Oxidative stress: cold temperatures (blue flake) and dormancy breaking reagents enhance ROS production, and ROS production inhibits dormancy maintenance.

the balance of these enzymes are central to the dormancy status and the growth potential of buds. Rinne et al. (2001, 2011) have hypothesized that the balance shifted toward net deposition as long as endodormancy lasts. Subsequently, during chillinginduced dormancy release, blocked plasmodesmata connections are restored within the bud by callose degradation. GAs seem to be implicated in the up-regulation of specific $1,3-\beta$-glucanases involved in orchestrating the chilling-induced callose breakdown to restore symplastic connections after endodormancy release (Rinne et al., 2011). By focusing on the ultra-structure of plasmodesmata Rinne et al. (2001) have shown that lipid bodies are targeted to the plasma membrane in close proximity to the plasmodesmata and may facilitate the restoration of plasmodesmata functionality (Rinne et al., 2011). Lipid droplets are membrane-bound storage organelles of universal occurrence. Recent analyses have suggested their role as signaling platforms that deliver proteins and signaling molecules (Murphy, 2012). In plants, they have been described as globules containing neutral lipids, triglycerids (TAG) or sterol esters, delimitated by a phospholipid monolayer (Farese and Walther, 2009; Chapman et al., 2012). van der Schoot et al. (2011) and Paul et al. (2014) have hypothesized that in buds, lipid bodies function as a vehicle that delivers proteins to the plasmodesmata, including 1,3 - $\beta$-glucanases to the callose deposits in order to restore plasmodesmata function (Rinne et al., 2011). Overall, explaining the establishment and release of dormancy by the dynamics of callose and plasmodesmata is tempting but genetic and molecular evidence to support this hypothesis are still lacking and causality remains unproven. Recently, observations on spruce embryonic shoots have revealed that callose was still detected in plasmodesmata during ecodormancy (Guzicka et al., 2017). Furthermore, recent studies on architecture and permeability of plasmodesmata have shed light on the fine mechanisms regulating cell-to-cell connectivity. They show that, although callose is a central regulator of plasmodesmata, it does not necessarily mediate all changes to connectivity and to the size exclusion limit (SEL) for the molecules (Tilsner et al., 2016; Nicolas et al., 2017).

To our knowledge, no published study has uncovered interactions between ROS signaling and intercellular transport 
during bud dormancy. However, these links have been firmly suggested in other systems. For example, Nicotiana benthamiana mutants exhibiting increased production of ROS also displayed higher plasmodesmal transport (Stonebloom et al., 2012). In Arabidopsis, a study measuring root cell permeability also supports the hypothesis that ROS amounts regulate plasmodesmata function: application of low concentrations of $\mathrm{H}_{2} \mathrm{O}_{2}$ increased plasmodesmata permeability whereas high $\mathrm{H}_{2} \mathrm{O}_{2}$ concentrations induced plasmodesmata closure (Rutschow et al., 2011). These results suggest that ROS may participate in promoting the formation and alteration of plasmodesmata, or callose deposit, thus controlling communication and transport. Rutschow et al. (2011) speculate that this signaling is linked to differential stress response: low amounts of ROS indicate mild stresses that might be mitigated by increased cellular transport while the response to extreme stressed revealed by acute ROS signals necessitates cellular isolation. For bud tissues, the question here is therefore which amount of ROS is produced during dormancy progression and release and how this signal is transduced for cellular transport.

\section{CONCLUSION}

Oxidative stress, carbohydrates metabolism highly linked to the mitochondrial respiration, hormones and transport capacity associated to plasma membrane and cell wall properties have been shown to play important roles in bud dormancy process. As these pathways interact between them, dormancy mechanism is very complex. The main pathways involved in bud dormancy are synthesized in Figure 3. Overall, these studies highlight the pivotal role of ROS production and detoxification systems for dormancy release. As a consequence of a combination of stresses

\section{REFERENCES}

Aloni, R., Baum, S. F., and Peterson, C. A. (1990). The role of cytokinin in sieve tube regeneration and callose production in wounded coleus internodes 1. Plant Physiol. 93, 982-989. doi: 10.1071/PP9930601

Alves, G., Améglio, T., Guilliot, A., Julien, J. L., Pétel, G., and Fleurat-Lessard, P. (2001). Cytological and immunological approach of vessel-associated cells in understanding the winter sugar exchanges, in walnut stems. Acta Hortic. 544, 295-300. doi: 10.17660/ActaHortic.2001.544.38

Alves, G., Decourteix, M., Fleurat-Lessard, P., Sakr, S., Bonhomme, M., Améglio, T., et al. (2007). Spatial activity and expression of plasma membrane $\mathrm{H}+$-ATPase in stem xylem of walnut during dormancy and growth resumption. Tree Physiol. 27, 1471-1480. doi: 10.1093/treephys/27.10.1471

Amooaghaie, R., and Ahmadi, F. (2017). Triangular interplay between ROS, ABA and GA in dormancy alleviation of Bunium persicum seeds by cold stratification. Russ. J. Plant Physiol. 64, 588-599. doi: 10.1134/S1021443717040021

Anderson, J. V., Horvath, D. P., Chao, W. S., and Foley, M. E. (2010). "Bud dormancy in perennial plants: a mechanism for survival," in Dormancy and Resistance in Harsh Environments, eds E. Lubzens, J. Cerda, and M. Clark (Berlin: Springer), 69-90. doi: 10.1007/978-3-642-12422-8_5

Arc, E., Galland, M., Cueff, G., Godin, B., Lounifi, I., Job, D., et al. (2011). Reboot the system thanks to protein post-translational modifications and proteome diversity: how quiescent seeds restart their metabolism to prepare seedling establishment. Proteomics 11, 1606-1618. doi: 10.1002/pmic.20100 0641 and the decrease of cell metabolism, dormant buds accumulate ROS and their removal by scavenging and detoxification systems seems to be associated with breaking of dormancy. Implication of these mechanisms is further validated by the action of $\mathrm{HC}$, potentially linked to the generation of sub-lethal oxidation stress. The question remains whether slow accumulation of ROS, as a consequence of winter temperatures and low metabolism, triggers dormancy release when a sub-lethal threshold is reached, or a prompt shift into stress-inducible conditions leads to a dormancy-alleviating response. In this case, the whole concept of chilling requirements could be questioned. Further studies are necessary to address these hypotheses, including the question of toxicity of dormancy-breaking treatments, in relation to ROS production.

\section{AUTHOR CONTRIBUTIONS}

$\mathrm{RB}, \mathrm{BW}$, and ED designed the manuscript. RB and BW wrote the manuscript. BW and ED critically evaluated the manuscript.

\section{FUNDING}

This work was supported by INRA and Aquitaine Region (AQUIPRU project 2014-1R20102-2971) for financing doctoral fellowships to RB.

\section{ACKNOWLEDGMENTS}

The authors would like to thank INRA and the Aquitaine Region for finding the financing doctoral fellowships to RB.

Aue, H.-L., Lecomte, I., and Pétel, G. (2000). Changes in parameters of the plasmalemma ATPase during peach vegetative bud dormancy. Biol. Plant. 43, 25-29. doi: 10.1023/A:1026538526649

Bahin, E., Bailly, C., Sotta, B., Kranner, I., Corbineau, F., and Leymarie, J. (2011). Crosstalk between reactive oxygen species and hormonal signalling pathways regulates grain dormancy in barley. Plant Cell Environ. 34, 980-993. doi: 10. 1111/j.1365-3040.2011.02298.x

Bai, S., Saito, T., Sakamoto, D., Fujii, H., and Moriguchi, T. (2013). Transcriptome analysis of Japanese pear (Pyrus pyrifolia Nakai.) flower buds transitioning through endodormancy. Plant Cell Physiol. 54, 1132-1151. doi: 10.1093/pcp/ pct067

Barba-Espin, G., Diaz-Vivancos, P., Clemente-Moreno, M. J., Albacete, A., Faize, L., Faize, M., et al. (2010). Interaction between hydrogen peroxide and plant hormones during germination and the early growth of pea seedlings. Plant Cell Environ. 33, 981-994. doi: 10.1111/j.1365-3040.2010.02120.x

Barros, M. H., Bandy, B., Tahara, E. B., and Kowaltowski, A. J. (2004). Higher respiratory activity decreases mitochondrial reactive oxygen release and increases life span in Saccharomyces cerevisiae. J. Biol. Chem. 279, 49883-49888. doi: 10.1074/jbc.M408918200

Bartolini, S., Vitagliano, C., Cinelli, F., and Scalabrelli, G. (1996). Effect of hydrogen cyanamide on apricot bud break and catalase activity. Acta Hortic. 441, 159166.

Bartolini, S., Zanol, G. C., and Viti, R. (2006). Changes in antioxidant compounds in flower buds of two apricot cultivars during winter season. Acta Hortic. 701, 69-74. doi: 10.17660/ActaHortic.2006.701.7 
Bielenberg, D. G., Wang, Y., Fan, S., Reighard, G. L., Scorza, R., and Abbott, A. G. (2004). A deletion affecting several gene candidates is present in the evergrowing peach mutant. J. Hered. 95, 436-444. doi: 10.1093/jhered/esh057

Bielenberg, D. G., Wang, Y., Li, Z., Zhebentyayeva, T., Fan, S., Reighard, G. L., et al. (2008). Sequencing and annotation of the evergrowing locus in peach (Prunus persica (L.) Batsch) reveals a cluster of six MADS-box transcription factors as candidate genes for regulation of terminal bud formation. Tree Genet. Genomes 4, 495-507. doi: 10.1007/s11295-007-0126-9

Böhlenius, H., Huang, T., Charbonnel-Campaa, L., Brunner, A. M., Jansson, S., Strauss, S. H., et al. (2006). CO/FT regulatory module controls timing of flowering and seasonal growth cessation in trees. Science 312, 1040-1043. doi: 10.1126/science. 1126038

Bonhomme, M., Rageau, R., and Gendraud, M. (2000). Influence of temperature on the dynamics of ATP, ADP and non-adenylic triphosphate nucleotides in vegetative and floral peach buds during dormancy. Tree Physiol. 20, 615-621. doi: 10.1093/treephys/20.9.615

Brown, D., Griggs, W., and Iwakiri, B. (1960). The influence of gibberellin on resting pear buds. Proc. Am. Soc. Hortic. 76, 52-58.

Chao, W. S., Doğramac1, M., Horvath, D. P., Anderson, J. V., and Foley, M. E. (2017). Comparison of phytohormone levels and transcript profiles during seasonal dormancy transitions in underground adventitious buds of leafy spurge. Plant Mol. Biol. 94, 281-302. doi: 10.1007/s11103-017-0607-7

Chapman, E., Wright, L. C., and Raison, J. K. (1979). Seasonal changes in the structure and function of mitochondrial membranes of artichoke tubers. Plant Physiol. 63, 363-366. doi: 10.1104/pp.63.2.363

Chapman, K. D., Dyer, J. M., and Mullens, R. T. (2012). Biogenesis and functions of lipid droplets in plants. J. Lipid Res. 53, 215-226. doi: 10.1194/jlr.R021436

Charrier, G., Chuine, I., Bonhomme, M., and Ameglio, T. (2017). Assessing frost damages using dynamic models in walnut trees: exposure rather than vulnerability controls frost risks. Plant Cell Environ. 41, 1008-1021. doi: $10.1111 /$ pce. 12935

Considine, M. J., and Considine, J. A. (2016). On the language and physiology of dormancy and quiescence in plants. J. Exp. Bot. 67, 3189-3203. doi: 10.1093/ jxb/erw138

Considine, M. J., Diaz-Vivancos, P., Kerchev, P., Signorelli, S., Agudelo-Romero, P., Gibbs, D. J., et al. (2017). Learning to breathe: developmental phase transitions in oxygen status. Trends Plant Sci. 22, 140-153. doi: 10.1016/j.tplants.2016.11. 013

Considine, M. J., and Foyer, C. H. (2014). Redox regulation of plant development. Antioxid. Redox Signal. 21, 1305-1326. doi: 10.1089/ars.2013.5665

Cooke, J. E., Eriksson, M. E., and Junttila, O. (2012). The dynamic nature of bud dormancy in trees: environmental control and molecular mechanisms. Plant Cell Environ. 35, 1707-1728. doi: 10.1111/j.1365-3040.2012.02552.x

Davies, D. R., Bindschedler, L. V., Strickland, T. S., and Bolwell, G. P. (2006). Production of reactive oxygen species in Arabidopsis thaliana cell suspension cultures in response to an elicitor from Fusarium oxysporum: implications for basal resistance. J. Exp. Bot. 57, 1817-1827. doi: 10.1093/jxb/erj216

Davies, P. J. (2013). Plant Hormones: Physiology, Biochemistry and Molecular Biology. Berlin: Springer Science \& Business Media.

Del Cueto, J., Ionescu, I. A., Pičmanová, M., Gericke, O., Motawia, M. S., Olsen, C. E., et al. (2017). Cyanogenic glucosides and derivatives in almond and sweet cherry flower buds from dormancy to flowering. Front. Plant Sci. 8:800. doi: 10.3389/fpls.2017.00800

Dieuaide, M., Brouquisse, R., Pradet, A., and Raymond, P. (1992). Increased Fatty Acid $\beta$-Oxidation after glucose starvation in maize root tips. Plant Physiol. 99, 595-600. doi: 10.1104/pp.99.2.595

Doğramacı, M., Foley, M. E., Chao, W. S., Christoffers, M. J., and Anderson, J. V. (2013). Induction of endodormancy in crown buds of leafy spurge (Euphorbia esula L.) implicates a role for ethylene and cross-talk between photoperiod and temperature. Plant Mol. Biol. 81, 577-593. 10.1007/s11103-0130026-3

Einali, A., and Valizadeh, J. (2017). Storage reserve mobilization, gluconeogenesis, and oxidative pattern in dormant pistachio (Pistacia vera L.) seeds during cold stratification. Trees 31, 659-671. doi: 10.1007/s00468-016-1498-y

El Kayal, W., Allen, C. C., Ju, C. J., Adams, E., King-Jones, S., Zaharia, L. I., et al. (2011). Molecular events of apical bud formation in white spruce. Picea glauca. Plant Cell Environ. 34, 480-500. doi: 10.1111/j.1365-3040.2010.02257.x
El-Shereif, A. R., Mizutani, F., Onguso, J. M., and Sharif Hossain, A. B. M. (2006). Influence of different temperatures on bud break and 1-aminocyclopropane-1carboxylic acid content of young peach trees. Acta Physiol. Plant. 28, 459-463. doi: 10.1007/BF02706629

Erez, A., Wang, S. Y., and Faust, M. (1997). Lipids in peach buds during dormancy, a possible involvement in dormancy control. Adv. Hortic. Sci. 11, 128-132.

Farese, R. V., and Walther, T. C. (2009). Lipid droplets finally get a little R-E-S-PE-C-T. Cell 139, 855-860. doi: 10.1016/j.cell.2009.11.005

Felker, F. C., Robitaille, H. A., and Hess, F. D. (1983). Morphological and ultrastructural development and starch accumulation during chilling of sour cherry flower buds. Am. J. Bot. 70, 376-386. doi: 10.2307/2443246

Fennell, A. Y., Schlauch, K. A., Gouthu, S., Deluc, L. G., Khadka, V., Sreekantan, L., et al. (2015). Short day transcriptomic programming during induction of dormancy in grapevine. Funct. Plant Ecol. 6:834. doi: 10.3389/fpls.2015.00834

Gévaudant, F., Pétel, G., and Guilliot, A. (2001). Differential expression of four members of the H+-ATPase gene family during dormancy of vegetative buds of peach trees. Planta 212, 619-626. doi: 10.1007/s004250000438

Giaquinta, R. T. (1979). Phloem Loading of Sucrose. Plant Physiol. 63, 744-748. doi: $10.1104 /$ pp.63.4.744

Götz, K.-P., Chmielewski, F.-M., Homann, T., Huschek, G., Matzneller, P., and Rawel, H. M. (2014). Seasonal changes of physiological parameters in sweet cherry (Prunus avium L.) buds. Sci. Hortic. 172, 183-190. doi: 10.1016/j.scienta. 2014.04.012

Guak, S., and Fuchigami, L. H. (2001). Effects of applied ABA on growth cessation, bud dormancy, cold acclimation, leaf senescence and $\mathrm{N}$ mobilization in apple nursery plants. J. Hortic. Sci. Biotechnol. 76, 459-464. doi: 10.1080/14620316. 2001.11511394

Guzicka, M. (2001). Changes in starch distribution within an embryonic shoot of Norway spruce [Picea abies (L.) Karst.] before resumption of mitotic activity. Dendrobiology 46, 27-31.

Guzicka, M., Pawłowski, T. A., Staszak, A., Rożkowski, R., and Chmura, D. J. (2017). Molecular and structural changes in vegetative buds of Norway spruce during dormancy in natural weather conditions. Tree Physiol. doi: 10.1093/ treephys/tpx156 [Epub ahead of print].

Halaly, T., Pang, X., Batikoff, T., Crane, O., Keren, A., Venkateswari, J., et al. (2008). Similar mechanisms might be triggered by alternative external stimuli that induce dormancy release in grape buds. Planta 228, 79-88. doi: 10.1007/ s00425-008-0720-6

Hao, X., Chao, W., Yang, Y., and Horvath, D. (2015). Coordinated expression of FLOWERING LOCUS T and DORMANCY ASSOCIATED MADS-BOXLike genes in Leafy Spurge. PLoS One 10:e0126030. doi: 10.1371/journal.pone. 0126030

Hao, X., Yang, Y., Yue, C., Wang, L., Horvath, D. P., and Wang, X. (2017) Comprehensive transcriptome analyses reveal differential gene expression profiles of Camellia sinensis axillary buds at para-, endo-, ecodormancy, and bud flush stages. Front. Plant Sci. 8:553. doi: 10.3389/fpls.2017.00553

Horvath, D. P., Chao, W. S., Suttle, J. C., Thimmapuram, J., and Anderson, J. V. (2008). Transcriptome analysis identifies novel responses and potential regulatory genes involved in seasonal dormancy transitions of leafy spurge (Euphorbia esula L.). BMC Genomics 9:536. doi: 10.1186/1471-2164-9-536

Howe, G. T., Horvath, D. P., Dharmawardhana, P., Priest, H. D., Mockler, T. C., and Strauss, S. H. (2015). Extensive transcriptome changes during natural onset and release of vegetative bud dormancy in Populus. Funct. Plant Ecol. 6:989. doi: 10.3389/fpls.2015.00989

Hsu, C.-Y., Adams, J. P., Kim, H., No, K., Ma, C., Strauss, S. H., et al. (2011). FLOWERING LOCUS T duplication coordinates reproductive and vegetative growth in perennial poplar. Proc. Natl. Acad. Sci. U.S.A. 108, 10756-10761. doi: 10.1073/pnas.1104713108

Huang, X., Zhu, W., Dai, S., Gai, S., Zheng, G., and Zheng, C. (2008). The involvement of mitochondrial phosphate transporter in accelerating bud dormancy release during chilling treatment of tree peony (Paeonia suffruticosa). Planta 228, 545-552. doi: 10.1007/s00425-008-0757-6

Hussain, S., Niu, Q., Yang, F., Hussain, N., and Teng, Y. (2015). The possible role of chilling in floral and vegetative bud dormancy release in Pyrus pyrifolia. Biol. Plant. 59, 726-734. doi: 10.1007/s10535-015-0547-5

Ionescu, I. A., López-Ortega, G., Burow, M., Bayo-Canha, A., Junge, A., Gericke, O., et al. (2017). Transcriptome and metabolite changes during 
hydrogen cyanamide-induced floral bud break in sweet cherry. Front. Plant Sci. 8:1233. doi: $10.3389 /$ fpls.2017.01233

Jian, L., Li, P. H., Sun, L., and Chen, T. H. (1997). Alterations in ultrastructure and subcellular localization of $\mathrm{Ca} 2+$ in poplar apical bud cells during the induction of dormancy. J. Exp. Bot. 48, 1195-1207. doi: 10.1093/jxb/48.6.1195

Jiménez, S., Reighard, G. L., and Bielenberg, D. G. (2010). Gene expression of DAM5 and DAM6 is suppressed by chilling temperatures and inversely correlated with bud break rate. Plant Mol. Biol. 73, 157-167. doi: 10.1007/ s11103-010-9608-5

Kaufmann, H., and Blanke, M. (2017). Changes in carbohydrate levels and relative water content (RWC) to distinguish dormancy phases in sweet cherry. J. Plant Physiol. 218, 1-5. doi: 10.1016/j.jplph.2017.07.004

Kawano, T. (2003). Roles of the reactive oxygen species-generating peroxidase reactions in plant defense and growth induction. Plant Cell Rep. 21, 829-837. doi: 10.1007/s00299-003-0591-z

Kocsy, G., von Ballmoos, P., Rüegsegger, A., Szalai, G., Galiba, G., and Brunold, C. (2001). Increasing the glutathione content in a chilling-sensitive maize genotype using safeners increased protection against chilling-induced injury. Plant Physiol. 127, 1147-1156. doi: 10.1104/pp.010107

Koussa, T., Broquedis, M., and Bouard, J. (1994). Importance de l'acide abscissique dans le developpement des bourgeons latents de vigne (Vitis vinifera L. var. Merlot) et plus particulierement dans la phase de levée de dormance. Vitis 33, 63-67.

Kuroda, H., Sugiura, T., and Ito, D. (2002). Changes in hydrogen peroxide content in flower buds of Japanese pear (Pyrus pyrifolia Nakai) in relation to breaking of endodormancy. J. Jpn. Soc. Hortic. Sci. 71, 610-616. doi: 10.2503/jjshs. 71.610

Kuroda, H., Sugiura, T., and Sugiura, H. (2005). Effect of Hydrogen peroxide on breaking endodormancy in flower buds of japanese pear (Pyrus pyrifolia Nakai). J. Jpn. Soc. Hortic. Sci. 74, 255-257. doi: 10.2503/jjshs.74.255

Lang, G., Early, J., Martin, G., and Darnell, R. (1987). Endo-, para-, and ecodormancy: physiological terminology and classification for dormancy research. Hortscience 22:377.

Le Bris, M., Michaux-Ferrière, N., Jacob, Y., Poupet, A., Barthe, P., Guigonis, J.-M., et al. (1999). Regulation of bud dormancy by manipulation of ABA in isolated buds of Rosa hybrida cultured in vitro. Aust. J. Plant Physiol. 26, 273-281. doi: 10.1071/PP98133

Leida, C., Conejero, A., Arbona, V., Gómez-Cadenas, A., Llácer, G., Badenes, M. L., et al. (2012). Chilling-Dependent release of seed and bud dormancy in peach associates to common changes in gene expression. PLoS One 7:e35777. doi: 10.1371/journal.pone.0035777

Leida, C., Terol, J., Martí, G., Agustí, M., Llácer, G., Badenes, M. L., et al. (2010). Identification of genes associated with bud dormancy release in Prunus persica by suppression subtractive hybridization. Tree Physiol. 30, 655-666. doi: 10.1093/treephys/tpq008

Li, J., Xu, Y., Niu, Q., He, L., Teng, Y., and Bai, S. (2018). Abscisic Acid (ABA) promotes the induction and maintenance of Pear (Pyrus pyrifolia White Pear Group) flower bud endodormancy. Int. J. Mol. Sci. 19:E310. doi: 10.3390/ ijms19010310

Li, Z., Reighard, G. L., Abbott, A. G., and Bielenberg, D. G. (2009). Dormancyassociated MADS genes from the EVG locus of peach (Prunus persica (L.) Batsch) have distinct seasonal and photoperiodic expression patterns. J. Exp. Bot. 60, 3521-3530. doi: 10.1093/jxb/erp195

Liu, B., Zhang, N., Wen, Y., Jin, X., Yang, J., Si, H., et al. (2015). Transcriptomic changes during tuber dormancy release process revealed by RNA sequencing in potato. J. Biotechnol. 198, 17-30. doi: 10.1016/j.jbiotec.2015.01.019

Liu, B., Zhao, S., Tan, F., Zhao, H., Wang, D., Si, H., et al. (2017). Changes in ROS production and antioxidant capacity during tuber sprouting in potato. Food Chem. 237, 205-213. doi: 10.1016/j.foodchem.2017.05.107

Liu, G., Li, W., Zheng, P., Xu, T., Chen, L., Liu, D., et al. (2012). Transcriptomic analysis of 'Suli'pear (Pyrus pyrifolia white pear group) buds during the dormancy by RNA-Seq. BMC Genomics 13:700. doi: 10.1186/1471-2164$13-700$

Liu, Y., Ye, N., Liu, R., Chen, M., and Zhang, J. (2010). H2O2 mediates the regulation of ABA catabolism and GA biosynthesis in Arabidopsis seed dormancy and germination. J. Exp. Bot. 61, 2979-2990. doi: 10.1093/jxb/erq125

Luna, V., Lorenzo, E., Reinoso, H., Tordable, M. C., Abdala, G., Pharis, R. P., et al. (1990). Dormancy in Peach (Prunus persica L.) flower buds: I. Floral morphogenesis and endogenous gibberellins at the end of the dormancy period. Plant Physiol. 93, 20-25. doi: 10.1104/pp.93.1.20

Marquat, C., Petel, G., and Gendraud, M. (1996). Study of H+-nutrient cotransport in peach-tree and the approach to their involvement in the expression of vegetative bud growth capability. J. Plant Physiol. 149, 102-108. doi: 10.1016/ S0176-1617(96)80180-5

Meinhard, M., and Grill, E. (2001). Hydrogen peroxide is a regulator of ABI1, a protein phosphatase 2C from Arabidopsis. FEBS Lett. 508, 443-446. doi: $10.1016 / 50014-5793(01) 03106-4$

Meitha, K., Agudelo-Romero, P., Signorelli, S., Gibbs, D. J., Considine, J. A., Foyer, C. H., et al. (2018). Developmental control of hypoxia during bud burst in grapevine. Plant Cell Environ. doi: 10.1111/pce.13141 [Epub ahead of print].

Meitha, K., Konnerup, D., Colmer, T. D., Considine, J. A., Foyer, C. H., and Considine, M. J. (2015). Spatio-temporal relief from hypoxia and production of reactive oxygen species during bud burst in grapevine (Vitis vinifera). Ann. Bot. 116, 703-711. doi: 10.1093/aob/mcv123

Mielke, E. A., and Dennis, F. G. (1978). Hormonal control of flower bud dormancy in sour cherry (Prunus cerasus L.). III. Effects of leaves, defoliation and temperature on levels of abscisic acid in flower primordia. J. Am. Soc. Hortic. Sci. 103, 446-449.

Mimida, N., Saito, T., Moriguchi, T., Suzuki, A., Komori, S., and Wada, M. (2015). Expression of DORMANCY-ASSOCIATED MADS-BOX (DAM)-like genes in apple. Biol. Plant. 59, 237-244. doi: 10.1007/s10535-015-0503-4

Mittler, R., Vanderauwera, S., Suzuki, N., Miller, G., Tognetti, V. B., Vandepoele, K., et al. (2011). ROS signaling: the new wave? Trends Plant Sci. 16, 300-309. doi: 10.1016/j.tplants.2011.03.007

Müller, K., Linkies, A., Vreeburg, R. A., Fry, S. C., Krieger-Liszkay, A., and LeubnerMetzger, G. (2009). In vivo cell wall loosening by hydroxyl radicals during cress seed germination and elongation growth. Plant Physiol. 150, 1855-1865. doi: 10.1104/pp.109.139204

Murcia, G., Pontin, M., Reinoso, H., Baraldi, R., Bertazza, G., Gómez-Talquenca, S., et al. (2015). ABA and GA3 increase carbon allocation in different organs of grapevine plants by inducing accumulation of non-structural carbohydrates in leaves, enhancement of phloem area and expression of sugar transporters. Physiol. Plant 156, 323-337. doi: 10.1111/ppl.12390

Murphy, D. J. (2012). The dynamic roles of intracellular lipid droplets: from archaea to mammals. Protoplasma 249, 541-585. doi: 10.1007/s00709-0110329-7

Nee, C.-C., and Fuchigami, L. H. (1992). Overcoming rest at different growth stages with hydrogen cyanamide. Sci. Hortic. 50, 107-113. doi: 10.1016/S03044238(05)80013-5

Nicolas, W. J., Grison, M. S., Trépout, S., Gaston, A., Fouché, M., Cordelières, F. P., et al. (2017). Architecture and permeability of post-cytokinesis plasmodesmata lacking cytoplasmic sleeves. Nat. Plants 3:17082. doi: 10.1038/nplants.20 17.82

Oncelay, C. Y., Daley, L. S., Vines, H. M., Couvillon, G. A., and Hendershott, C. H. (1979). Seasonal fluctuation in malate dehydrogenase, phosphatase and proteinase activity of dormant peach flower buds. Sci. Hortic. 11, 229-239. doi: 10.1016/0304-4238(79)90004-9

Ophir, R., Pang, X., Halaly, T., Venkateswari, J., Lavee, S., Galbraith, D., et al. (2009). Gene-expression profiling of grape bud response to two alternative dormancy-release stimuli expose possible links between impaired mitochondrial activity, hypoxia, ethylene-ABA interplay and cell enlargement. Plant Mol. Biol. 71, 403-423. 10.1007/s11103-0099531-9

Or, E., Vilozny, I., Eyal, Y., and Ogrodovitch, A. (2000). The transduction of the signal for grape bud dormancy breaking induced by hydrogen cyanamide may involve the SNF-like protein kinase GDBRPK. Plant Mol. Biol. 43, 483-494. doi: 10.1023/A:1006450516982

Oracz, K., El-Maarouf Bouteau, H., Farrant, J. M., Cooper, K., Belghazi, M., Job, C., et al. (2007). ROS production and protein oxidation as a novel mechanism for seed dormancy alleviation: dormancy in sunflower seeds. Plant J. 50, 452-465. doi: 10.1111/j.1365-313X.2007.03063.x

Oracz, K., and Karpiński, S. (2016). Phytohormones signaling pathways and ROS involvement in seed germination. Front. Plant Sci. 7:864. doi: 10.3389/fpls.2016. 00864

Orffer, C. J., and Goussard, P. G. (1980). Effect of hot-water treatments on budburst and rooting of grapevine cuttings. Vitis 19, 1-3. 
Parada, F., Noriega, X., Dantas, D., Bressan-Smith, R., and Pérez, F. J. (2016). Differences in respiration between dormant and non-dormant buds suggest the involvement of ABA in the development of endodormancy in grapevines. J. Plant Physiol. 201, 71-78. doi: 10.1016/j.jplph.2016.07.007

Park, J.-Y., Canam, T., Kang, K.-Y., Unda, F., and Mansfield, S. D. (2009). Sucrose phosphate synthase expression influences poplar phenology. Tree Physiol. 29, 937-946. doi: 10.1093/treephys/tpp028

Paul, L. K., Rinne, P. L., and van der Schoot, C. (2014). Shoot meristems of deciduous woody perennials: self-organization and morphogenetic transitions. Curr. Opin. Plant Biol. 17, 86-95. doi: 10.1016/j.pbi.2013.11.009

Pérez, F. J., and Burgos, B. (2004). Alterations in the pattern of peroxidase isoenzymes and transient increases in its activity and in $\mathrm{H} 2 \mathrm{O} 2$ levels take place during the dormancy cycle of grapevine buds: the effect of hydrogen cyanamide. Plant Growth Regul. 43, 213-220. doi: 10.1023/B:GROW.0000046003.33194.ac

Pérez, F. J., and Lira, W. (2005). Possible role of catalase in post-dormancy bud break in grapevines. J. Plant Physiol. 162, 301-308. doi: 10.1016/j.jplph.2004.07. 011

Pérez, F. J., Vergara, R., and Or, E. (2009). On the mechanism of dormancy release in grapevine buds: a comparative study between hydrogen cyanamide and sodium azide. Plant Growth Regul. 59, 145-152. doi: 10.1007/s10725-0099397-5

Pérez, F. J., Vergara, R., and Rubio, S. (2008). H2O2 is involved in the dormancybreaking effect of hydrogen cyanamide in grapevine buds. Plant Growth Regul. 55, 149-155. doi: 10.1007/s10725-008-9269-4

Pfeiffer, W., and Höftberger, M. (2001). Oxidative burst in Chenopodium rubrum suspension cells. Physiol. Plant. 111, 144-150. doi: 10.1034/j.1399-3054.2001. 1110203.x

Piola, F., Label, P., Vergne, P., Aderkas, P., and von Rohr, R. (1998). Effects of endogenous ABA levels and temperature on cedar (Cedrus libani Loudon) bud dormancy in vitro. Plant Cell Rep. 18, 279-283. doi: 10.1007/s00299005 0571

Porto, D. D., Bruneau, M., Perini, P., Anzanello, R., Renou, J.-P., dos, et al. (2015). Transcription profiling of the chilling requirement for bud break in apples: a putative role for FLC-like genes. J. Exp. Bot. 66, 2659-2672. doi: 10.1093/jxb/ erv061

Portrat, K., Mathieu, C., Motta, C., and Pétel, G. (1995). Changes in plasma membrane properties of peach tree buds and stands during dormancy. J. Plant Physiol. 147, 346-350. doi: 10.1016/S0176-1617(11)82165-6

Pouget, R. (1965). Action de la chlorpromazine sur la dormance de la vigne (Vitis vinifera L.). Ann. Physiol. Vég. 7, 273-282.

Prassinos, C., Rigas, S., Kizis, D., Vlahou, A., and Hatzopoulos, P. (2011). Subtle proteome differences identified between post-dormant vegetative and floral peach buds. J. Proteomics 74, 607-619. doi: 10.1016/j.jprot.2011.01.018

Ramina, A., Colauzzi, M., Masia, A., Pitacco, A., Caruso, T., Messina, R., et al. (1995). Hormonal and climatological aspects of dormancy in peach buds. Acta Hortic. 395, 35-46. doi: 10.17660/ActaHortic.1995.395.3

Regier, N., Streb, S., Zeeman, S. C., and Frey, B. (2010). Seasonal changes in starch and sugar content of poplar (Populus deltoides $\times$ nigra cv. Dorskamp) and the impact of stem girdling on carbohydrate allocation to roots. Tree Physiol. 30, 979-987. doi: 10.1093/treephys/tpq047

Reinoso, H., Luna, V., Daurfa, C., Pharis, R., and Bottini, R. (2002). Dormancy in peach (Prunus persica) flower buds. VI. Effects of gibberellins and an acylcyclohexanedione (trinexapac-ethyl) on bud morphogenesis in field experiments with orchard trees and on cuttings. Can. J. Bot. 80, 664-674. doi: 10.1139/B02-051

Rinne, P., Tuominen, H., and Junttila, O. (1994). Seasonal changes in bud dormancy in relation to bud morphology, water and starch content, and abscisic acid concentration in adult trees of Betula pubescens. Tree Physiol. 14, 549-561. doi: 10.1093/treephys/14.6.549

Rinne, P. L., Kaikuranta, P. M., and van der Schoot, C. (2001). The shoot apical meristem restores its symplasmic organization during chilling-induced release from dormancy. Plant J. 26, 249-264. doi: 10.1046/j.1365-313X.2001.01022.x

Rinne, P. L., and van der Schoot, C. (1998). Symplasmic fields in the tunica of the shoot apical meristem coordinate morphogenetic events. Development 125 , 1477-1485.

Rinne, P. L., and van der Schoot, C. (2003). Plasmodesmata at the crossroads between development, dormancy, and defense. Can. J. Bot. 81, 1182-1197. doi: $10.1139 / \mathrm{b} 03-123$
Rinne, P. L., and van der Schoot, C. (2004). Cell-cell communication as a key factor in dormancy cycling. J. Crop Improv. 10, 113-156. doi: 10.1300/J411v10n01

Rinne, P. L., Welling, A., Vahala, J., Ripel, L., Ruonala, R., Kangasjärvi, J., et al. (2011). Chilling of dormant buds hyperinduces FLOWERING LOCUS T and recruits GA-inducible $1,3-\beta$-glucanases to reopen signal conduits and release dormancy in Populus. Plant Cell 23, 130-146. doi: 10.1105/tpc.110.081307

Rios, G., Conejero, A., Leida, C., Petri, C., Burgos, L., and Badenes, M. L. (2014). "Functional characterization of a SAP protein expressed in dormant buds of peach," in Proceedings of the 7th International Rosaceae Genomics Conference, Washington, DC, 20.

Rodríguez, A., and Sánchez-Tamés, R. (1986). Dormancy and seasonal changes of plant growth regulators in hazel buds. Physiol. Plant. 66, 288-292. doi: 10.1111/ j.1399-3054.1986.tb02422.x

Rodriguez, A. J., Sherman, W. B., Scorza, R., Wisniewski, M., and Okie, W. R. (1994). Evergreen' Peach, its inheritance and dormant behavior. J. Am. Soc. Hortic. Sci. 119, 789-792.

Rodríguez-Gacio Mdel, C., Matilla-Vázquez, M. A., and Matilla, A. J. (2009). Seed dormancy and ABA signaling: the breakthrough goes on. Plant Signal. Behav. 4, 1035-1048. doi: 10.4161/psb.4.11.9902

Rohde, A., Ruttink, T., Hostyn, V., Sterck, L., Van Driessche, K., and Boerjan, W. (2007). Gene expression during the induction, maintenance, and release of dormancy in apical buds of poplar. J. Exp. Bot. 58, 4047-4060. doi: 10.1093/ jxb/erm 261

Rubio, S., Donoso, A., and Pérez, F. J. (2014). The dormancy-breaking stimuli "chilling, hypoxia and cyanamide exposure" up-regulate the expression of $\alpha$-amylase genes in grapevine buds. J. Plant Physiol. 171, 373-381. doi: 10.1016/ j.jplph.2013.11.009

Rutschow, H. L., Baskin, T. I., and Kramer, E. M. (2011). Regulation of solute flux through plasmodesmata in the root meristem. Plant Physiol. 155, 1817-1826. doi: $10.1104 /$ pp.110.168.168187

Ruttink, T., Arend, M., Morreel, K., Storme, V., Rombauts, S., Fromm, J., et al. (2007). A molecular timetable for apical bud formation and dormancy induction in poplar. Plant Cell 19, 2370-2390. doi: 10.1105/tpc.107.05 2811

Saito, T., Bai, S., Imai, T., Ito, A., Nakajima, I., and Moriguchi, T. (2015). Histone modification and signalling cascade of the dormancy-associated MADS-box gene, PpMADS13-1, in Japanese pear (Pyrus pyrifolia) during endodormancy. Plant Cell Environ. 38, 1157-1166. doi: 10.1111/pce.12469

Saito, T., Bai, S., Ito, A., Sakamoto, D., Saito, T., Ubi, B. E., et al. (2013). Expression and genomic structure of the dormancy-associated MADS box genes MADS13 in Japanese pears (Pyrus pyrifolia Nakai) that differ in their chilling requirement for endodormancy release. Tree Physiol. 33, 654-667. doi: 10.1093/treephys/ tpt037

Sanchez-Perez, R., Del Cueto, J., Dicenta, F., and Martinez-Gomez, P. (2014). Recent advancements to study flowering time in almond and other Prunus species. Front. Plant Sci. 5:334. doi: 10.3389/fpls.2014.00334

Sasaki, R., Yamane, H., Ooka, T., Jotatsu, H., Kitamura, Y., Akagi, T., et al. (2011). Functional and expressional analyses of PmDAM genes associated with endodormancy in Japanese apricot. Plant Physiol. 157, 485-497. doi: 10.1104/ pp.111.181982

Saure, M. C. (1985). "Dormancy release in deciduous fruit trees," in Horticultural Reviews, ed. J. Janick (Hoboken, NJ: John Wiley \& Sons, Inc.), 239-300. doi: 10.1002/9781118060735.ch6.

Scalabrelli, G., Viti, R., and Cinelli, F. (1991). Change in the catalase activity and dormancy of apricot buds in response to chilling. Acta Hortic. 293, 267-274. doi: 10.17660/ActaHortic.1991.293.31

Seif El-Yazal, M. A., Seif El-Yazal, S. A., and Rady, M. M. (2014). Exogenous dormancy-breaking substances positively change endogenous phytohormones and amino acids during dormancy release in 'Anna' apple trees. Plant Growth Regul. 72, 211-220. doi: 10.1007/s10725-013-9852-1

Signorelli, S., Agudelo-Romero, P., Meitha, K., Foyer, C. H., and Considine, M. J. (2018). Roles for light, energy, and oxygen in the fate of quiescent axillary buds. Plant Physiol. 176, 1171-1181. doi: 10.1104/pp.17.01479

Siller-Cepeda, J. H., Fuchigami, L. H., and Chen, T. H. (1992). Glutathione content in peach buds in relation to development and release of rest. Plant Cell Physiol. $33,867-872$.

Srinivasan, C., Dardick, C., Callahan, A., and Scorza, R. (2012). Plum (Prunus domestica) trees transformed with poplar FT1 result in altered architecture, 
dormancy requirement, and continuous flowering. PLoS One 7:e40715. doi: 10.1371/journal.pone.0040715

Stonebloom, S., Brunkard, A., Cheung, A. C., Jiang, K., and Zambryski, P. (2012). Redox states of plastids and mitochondria differentially regulate intercellular transport via plasmodesmata. Plant Physiol. 158, 190-199. doi: 10.1104/pp.111. 186130

Sudawan, B., Chang, C.-S., Chao, H. F., Ku, M. S. B., and Yen, Y. (2016). Hydrogen cyanamide breaks grapevine bud dormancy in the summer through transient activation of gene expression and accumulation of reactive oxygen and nitrogen species. BMC Plant Biol. 16:202. doi: 10.1186/s12870-016-0889-y

Tan, Y., Gao, D.-S., Li, L., Wei, H.-R., Wang, J.-W., and Liu, Q.-Z. (2015). Relationships between $\mathrm{H} 2 \mathrm{O} 2$ metabolism and $\mathrm{Ca} 2+$ transport in dormancybreaking process of nectarine floral buds. Researchgate 26, 425-429.

Tarancón, C., González-Grandío, E., Oliveros, J. C., Nicolas, M., and Cubas, P. (2017). A conserved carbon starvation response underlies bud dormancy in woody and Herbaceous Species. Front. Plant Sci. 8:788. doi: 10.3389/fpls.2017. 00788

Tilsner, J., Nicolas, W., Rosado, A., and Bayer, E. M. (2016). Staying tight: plasmodesmal membrane contact sites and the control of cell-to-cell connectivity in plants. Annu. Rev. Plant Biol. 67, 337-364. doi: 10.1146/ annurev-arplant-043015

Tuan, P. A., Bai, S., Saito, T., Ito, A., and Moriguchi, T. (2017). DormancyAssociated MADS-Box (DAM) and the abscisic acid pathway regulate pear endodormancy through a feedback mechanism. Plant Cell Physiol. 58, 1378-1390. doi: $10.1093 / \mathrm{pcp} / \mathrm{pcx} 074$

Turrens, J. F. (2003). Mitochondrial formation of reactive oxygen species. J. Physiol. 552, 335-344. doi: 10.1111/j.1469-7793.2003.00335.x

Ubi, B. E., Sakamoto, D., Ban, Y., Shimada, T., Ito, A., Nakajima, I., et al. (2010). Molecular cloning of dormancy-associated mads-box gene homologs and their characterization during seasonal endodormancy transitional phases of Japanese pear. J. Am. Soc. Hortic. Sci. 135, 174-182.

Uemura, M., and Steponkus, P. L. (1999). Cold acclimation in plants: relationship between the lipid composition and the cryostability of the plasma membrane. J. Plant Res. 112, 245-254. doi: 10.1007/PL00013882

Van Aken, O., Zhang, B., Carrie, C., Uggalla, V., Paynter, E., Giraud, E., et al. (2009). Defining the mitochondrial stress response in Arabidopsis thaliana. Mol. Plant 2, 1310-1324. doi: 10.1093/mp/ssp053

van der Schoot, C., Paul, L. K., Paul, S. B., and Rinne, P. L. (2011). Plant lipid bodies and cell-cell signaling. Plant Signal. Behav. 6, 1732-1738. doi: 10.4161/psb.6.11. 17639

Vergara, R., Rubio, S., and Pérez, F. J. (2012). Hypoxia and hydrogen cyanamide induce bud-break and up-regulate hypoxic responsive genes (HRG) and VvFT in grapevine-buds. Plant Mol. Biol. 79, 171-178. doi: 10.1007/s11103012-9904-3

Viti, R., Bartolini, S., and Zanol, G. C. (2012). Biological changes and active oxygen-scavenging enzymes activities in apricot (Prunus armeniaca L.) flower buds during dormancy transitions. Acta Hortic. 940, 331-339. doi: 10.17660/ ActaHortic.2012.940.47

Wang, D., Gao, Z., Du, P., Xiao, W., Tan, Q., Chen, X., et al. (2016). Expression of ABA metabolism-related genes suggests similarities and differences between seed dormancy and bud dormancy of peach (Prunus persica). Crop Sci. Hortic. 6:1248. doi: 10.3389/fpls.2015.01248

Wang, M., van der Meulen, R. M., Visser, K., Van Schaik, H. P., Van Duijn, B., and de Boer, A. H. (1998). Effects of dormancy-breaking chemicals on ABA levels in barley grain embryos. Seed Sci. Res. 8, 129-137. doi: 10.1017/ S0960258500004025

Wang, S. Y., and Faust, M. (1988). Changes of fatty acids and sterols in apple buds during bud break induced by a plant bioregulator, thidiazuron. Physiol. Plant. 72, 115-120. doi: 10.1111/j.1399-3054.1988.tb06631.x

Wang, S. Y., and Faust, M. (1990). Changes of membrane lipids in apple buds during dormancy and budbreak. J. Am. Soc. Hortic. Sci. 115, 803-808.

Wang, S. Y., and Faust, M. (1994). Changes in polyamine content during dormancy in flower buds of 'Anna'. Apple. J. Am. Soc. Hortic. Sci. 119, 70-73.

Wang, S. Y., Ji, Z. L., Sun, T., and Faust, M. (1987). Effect of thidiazuron on abscisic acid content in apple bud relative to dormancy. Physiol. Plant. 71, 105-109. doi: 10.1111/j.1399-3054.1987.tb04625.x

Wen, L. H., Zhong, W. J., Huo, X. M., Zhuang, W. B., Ni, Z. J., and Gao, Z. H. (2016). Expression analysis of ABA- and GA-related genes during four stages of bud dormancy in Japanese apricot (Prunus mume Sieb. et Zucc). J. Hortic. Sci. Biotechnol. 91, 362-369. doi: 10.1080/14620316.2016.1160546
Wisniewski, M., and Ashworth, E. N. (1986). A comparison of seasonal ultrastructural changes in stem tissues of peach (Prunus persica) that exhibit contrasting mechanisms of cold hardiness. Bot. Gaz. 147, 407-417. doi: 10.1086/ 337608

Wisniewski, M., Norelli, J., and Artlip, T. (2015). ). Overexpression of a peach CBF gene in apple: a model for understanding the integration of growth, dormancy, and cold hardiness in woody plants. Front. Plant Sci. 6:85. doi: 10.3389/fpls. 2015.00085

Wu, R., Wang, T., Warren, B. A. W., Allan, A. C., Macknight, R. C., and VarkonyiGasic, E. (2017). Kiwifruit SVP2 gene prevents premature budbreak during dormancy. J. Exp. Bot. 68, 1071-1082. doi: 10.1093/jxb/erx014

Xu, H., Cao, D., Chen, Y., Wei, D., Wang, Y., Stevenson, R. A., et al. (2016). Gene expression and proteomic analysis of shoot apical meristem transition from dormancy to activation in Cunninghamia lanceolata (Lamb.) Hook. Sci. Rep. 6:19938. doi: 10.1038/srep19938

Yamane, H., Kashiwa, Y., Ooka, T., Tao, R., and Yonemori, K. (2008). Suppression subtractive hybridization and differential screening reveals endodormancy-associated expression of an SVP/AGL24-type MADS-box gene in lateral vegetative buds of Japanese apricot. J. Am. Soc. Hortic. Sci. 133, $708-716$.

Yooyongwech, S., Horigane, A. K., Yoshida, M., Sekozawa, Y., Sugaya, S., Chaum, S., et al. (2012). Hydrogen cyanamide enhances MRI-measured water status in flower buds of peach (Prunus persica L.) during winter. Plant Omics 5, 400-404.

Yooyongwech, S., Horigane, A. K., Yoshida, M., Yamaguchi, M., Sekozawa, Y., Sugaya, S., et al. (2008). Changes in aquaporin gene expression and magnetic resonance imaging of water status in peach tree flower buds during dormancy. Physiol. Plant. 134, 522-533. 10.1111/j.1399-3054.2008. 01143.x

Yooyongwech, S., Sugaya, S., Sekozawa, Y., and Gemma, H. (2009). Differential adaptation of high-and low-chill dormant peaches in winter through aquaporin gene expression and soluble sugar content. Plant Cell Rep. 28, 1709-1715. doi: 10.1007/s00299-009-0770-7

Zanol, G. C., Sekozawa, Y., Sugaya, S., and Gemma, H. (2010). The glutathione accumulation on mixed bud tissues during the dormancy of Japanese pear. Acta Hortic. 872, 77-84. doi: 10.17660/ActaHortic.2010.872.7

Zhang, Y., Sun, T., Liu, S., Dong, L., Liu, C., Song, W., et al. (2016). MYC cis-Elements in PsMPT promoter is involved in chilling response of Paeonia suffruticosa. PLoS One 11:e0155780. doi: 10.1371/journal.pone.0155780

Zhang, Y. X., Yu, D., Tian, X. L., Liu, C. Y., Gai, S. P., and Zheng, G. S. (2015). Differential expression proteins associated with bud dormancy release during chilling treatment of tree peony (Paeonia suffruticosa). Plant Biol. 17, 114-122. doi: $10.1111 /$ plb.12213

Zheng, C., Halaly, T., Acheampong, A. K., Takebayashi, Y., Jikumaru, Y., Kamiya, Y., et al. (2015). Abscisic acid (ABA) regulates grape bud dormancy, and dormancy release stimuli may act through modification of ABA metabolism. J. Exp. Bot. 66, 1527-1542. doi: 10.1093/jxb/eru519

Zhong, W., Gao, Z., Zhuang, W., Shi, T., Zhang, Z., and Ni, Z. (2013). Genomewide expression profiles of seasonal bud dormancy at four critical stages in Japanese apricot. Plant Mol. Biol. 83, 247-264. doi: 10.1007/s11103-013-0 086-4

Zhuang, W., Gao, Z., Wang, L., Zhong, W., Ni, Z., and Zhang, Z. (2013). Comparative proteomic and transcriptomic approaches to address the active role of GA4 in Japanese apricot flower bud dormancy release. J. Exp. Bot. 64, 4953-4966. doi: 10.1093/jxb/ert284

Zhuang, W., Gao, Z., Wen, L., Huo, X., Cai, B., and Zhang, Z. (2015). Metabolic changes upon flower bud break in Japanese apricot are enhanced by exogenous GA4. Hortic. Res. 2:15046. doi: 10.1038/hortres.2015.46

Conflict of Interest Statement: The authors declare that the research was conducted in the absence of any commercial or financial relationships that could be construed as a potential conflict of interest.

Copyright (c) 2018 Beauvieux, Wenden and Dirlewanger. This is an open-access article distributed under the terms of the Creative Commons Attribution License (CC BY). The use, distribution or reproduction in other forums is permitted, provided the original author(s) and the copyright owner are credited and that the original publication in this journal is cited, in accordance with accepted academic practice. No use, distribution or reproduction is permitted which does not comply with these terms. 